\title{
Microcontaminant degradation in municipal wastewater treatment plant secondary effluent by EDDS assisted photo-Fenton at near-neutral pH: An experimental design approach
}

\author{
S. Papoutsakis ${ }^{\text {b,d }}$, S. Miralles-Cuevas ${ }^{\text {a }}$, I. Oller ${ }^{\mathrm{a}, \mathrm{d}}$, J.L. Garcia Sanchez ${ }^{\mathrm{c}}$, C. Pulgarin $^{\mathrm{b}}$, \\ S. Malato ${ }^{\mathrm{a}, \mathrm{d}, *}$ \\ a Plataforma Solar de Almeria - CIEMAT, Carretera de Senés, km 4, 04200 Tabernas, Spain \\ ${ }^{\mathrm{b}}$ Ecole Polytechnique Fédérale de Lausanne, ISIC, Station 6, CH-1015 Lausanne, Switzerland \\ c Departamento de Ingeniería Química de la Universidad de Almería, Carretera Sacramento S/N, 04120 Almería, Spain \\ d CIESOL, Joint Centre of the University of Almería-CIEMAT, 04120 Almería, Spain
}

\section{A R T I C L E I N F O}

\section{Article history:}

Received 14 July 2014

Received in revised form 5 February 2015

Accepted 6 February 2015

Available online 28 February 2015

\section{Keywords:}

Advanced oxidation processes (AOP)

Iron complexes

Photo-Fenton

Municipal wastewater treatment

\begin{abstract}
A B S T R A C T
This work aims to evaluate the applicability of EDDS (ethylenediamine-N, $\mathrm{N}^{\prime}$-disuccinic acid) as an iron chelating agent for photo-Fenton treatment of municipal wastewater spiked with organic contaminants at near-neutral $\mathrm{pH}$. A series of laboratory scale experiments are conducted under simulated sunlight in accordance with a central composite experimental design in order to define the most favorable conditions in terms of initial iron concentration (maintaining a molar ratio 1:2 of Fe:EDDS), $\mathrm{H}_{2} \mathrm{O}_{2}$ and pH. The system is evaluated in terms of degradation efficiency, $\mathrm{H}_{2} \mathrm{O}_{2}$ consumption and iron availability. The simulated system has been compared in terms of degradation efficiency with a $60 \mathrm{~L}$ compound parabolic collector (CPC), and significant correlation has been observed. An approach for estimating near-optimal regions of operability is also demonstrated.
\end{abstract}

(C) 2015 Elsevier B.V. All rights reserved.

\section{Introduction}

The inability of conventional wastewater treatment facilities to fully eliminate recalcitrant organic contaminants has been a source of growing concern in recent years. Compounds found in common household, agricultural or pharmaceutical products are found in wastewater plant effluent streams prior to release into the aquatic environment. Even though the concentrations in which they are found is usually in the ng to $\mu \mathrm{g}$ per liter scale, their continuous disposal unavoidably leads to accumulation in natural waters, provoking potential long-term health and ecological risks [1-3].

Advanced oxidation processes (AOPs) are a promising set of processes considered for application as part of tertiary treatment of effluents coming from municipal wastewater treatment plants (MWTP) [4-7]. Their capacity to generate highly reactive, non-selective reactive oxygen species (ROS), mainly $\mathrm{HO}^{\bullet}$ lead to the chemical elimination of biologically recalcitrant contaminants, increasing biodegradability of effluent streams. The Fenton process is an AOP, in which the production of ROS is driven by the iron

\footnotetext{
* Corresponding author: Tel.: +34 950387940; fax: +34 950365015

E-mail address: Sixto.malato@psa.es (S. Malato).
}

mediated decomposition of $\mathrm{H}_{2} \mathrm{O}_{2}$, with the following reactions taking place in solution (React. 1):

$$
\begin{aligned}
& \mathrm{Fe}^{2+}+\mathrm{H}_{2} \mathrm{O}_{2} \rightarrow \mathrm{Fe}^{3+}+\mathrm{OH}^{-}+\mathrm{HO} \\
& \mathrm{Fe}^{3+}+\mathrm{H}_{2} \mathrm{O}_{2} \rightarrow \mathrm{Fe}^{2+}+\mathrm{HO}_{2} \bullet+\mathrm{H}^{+} \\
& \mathrm{HO}+\mathrm{H}_{2} \mathrm{O}_{2} \rightarrow \mathrm{HO}_{2} \bullet+\mathrm{H}_{2} \mathrm{O} \\
& \mathrm{HO}+\mathrm{Fe}^{2+} \rightarrow \mathrm{Fe}^{3+} \mathrm{OH}^{-} \\
& \mathrm{Fe}^{3+}+\mathrm{HO}_{2}^{\bullet} \rightarrow \mathrm{Fe}^{2+}+\mathrm{O}_{2} \mathrm{H}^{+} \\
& \mathrm{Fe}^{2+}+\mathrm{HO}_{2}^{\bullet}+\mathrm{H}+\rightarrow \mathrm{Fe}^{3+}+\mathrm{H}_{2} \mathrm{O}_{2} \\
& \mathrm{HO}_{2}{ }^{\bullet}+\mathrm{HO}_{2} \bullet \rightarrow \mathrm{H}_{2} \mathrm{O}_{2}+\mathrm{O}_{2}
\end{aligned}
$$

As seen in (Reacts. 1-7), generation of hydroxyl and hydroperoxyl radicals is dependent on the cycling of iron between the $\mathrm{Fe}^{2+}$ and $\mathrm{Fe}^{3+}$ states. However, as (React. 1) is several orders of magnitude faster than (Reacts. 2-7), iron remains primarily as $\mathrm{Fe}^{3+}$, effectively stopping the process.

In water, $\mathrm{Fe}^{3+}$ is subjected to extensive hydrolysis, forming different $\mathrm{Fe}^{3+}$-aqua complexes depending on $\mathrm{pH}$. At $\mathrm{pH}$ around 3, $\left[\mathrm{Fe}\left(\mathrm{H}_{2} \mathrm{O}\right)_{5}(\mathrm{OH})\right]^{2+}$ is the predominant species, which exhibits significant photoactivity in the UV and visible region of solar radiation 
[8] Under illumination, $\mathrm{Fe}^{2+}$ is regenerated in a variant called the photo-Fenton (React. 8)

$\left[\mathrm{Fe}\left(\mathrm{H}_{2} \mathrm{O}\right)_{5}(\mathrm{OH})\right]^{2+}+\mathrm{hv} \rightarrow \mathrm{Fe}^{2+}+\mathrm{H}^{+}+\mathrm{HO}^{\bullet}$

The main limitation of the photo-Fenton process is the necessity to maintain the $\mathrm{pH}$ acidic throughout the treatment, as $\mathrm{Fe}^{3+}$-aqua complexes tend to precipitate above $\mathrm{pH} 3$ [9]. The acidified effluent also has to be neutralized before releasing to the environment. This introduces significant drawbacks in terms of reagent costs, operational complexity as well as the reduced quality of the treated water due to higher salt content.

The use of organic iron-complexing ligands has recently been gaining interest as a means of enhancing the performance of photo-Fenton photocatalytic systems [10]. Compared with $\mathrm{Fe}^{3+}$ aqua complexes, $\mathrm{Fe}^{3+}$-organic ligand complexes can maintain their solubility at a wider $\mathrm{pH}$ range, limiting the need for acidification and $\mathrm{pH}$ control. Additionally, many of them exhibit improved quantum yields, and photoactivity in a wider fraction of the solar spectrum, up to $580 \mathrm{~nm}$. The generalized photo-Fenton reaction is presented below (React. 9)

$\mathrm{Fe}^{3+}-\mathrm{L}+\mathrm{hv} \rightarrow \mathrm{Fe}^{2+}-(\mathrm{L})_{n-1}+\mathrm{L}^{\bullet}$

Among the most well studied ligands are oxalic acid [11,12] and citric acid $[13,14]$. Although both are capable of maintaining iron soluble at neutral $\mathrm{pH}$, the optimal behavior of $\mathrm{Fe}(\mathrm{III})$-citrate and $\mathrm{Fe}(\mathrm{III})$-oxalate photochemical processes are still under slightly acidic $\mathrm{pH}$ (5.0 for $\mathrm{Fe}(\mathrm{III})$-citrate and 4.3 for $\mathrm{Fe}(\mathrm{III})$-oxalate) $[15,16]$. Treatment of the near neutral MWTP effluent would therefore not be optimal. Additionally, the use of oxalic acid could introduce significant toxicity concerns [17]. The complex fraction of natural organic matter known as humic acids has also attracted some interest due to its ubiquitous presence in natural waters $[18,19]$. Treatment of heavily contaminated industrial wastewater has been shown to be efficient at neutral $\mathrm{pH}$ with the addition of humic acids [20]. However, for treating contaminants at the $\mu \mathrm{g} \mathrm{L}^{-1}$ level in neutral pH MWTP effluent, degradation rate was slow and the residual $\mathrm{pH}$ acidic, requiring adjustment prior to release [21].

Of particular interest are aminopolycarboxylic acids (APCAs), which can form stable water-soluble complexes over a wide $\mathrm{pH}$ range. Ethylenediaminetetraacetic acid (EDTA) has been extended in industrial applications due to its ability to solubilize and inactivate metal ions. However, due to its high biorecalcitrance, it has been classified as a persistent pollutant $[22,23]$. An alternative APCA, ethylenediamine-N, $\mathrm{N}^{\prime}$-disuccinic acid (EDDS) has metal complexing properties similar to EDTA, but is biodegradable and considered environmentally safe $[24,25]$. Due to these favorable characteristics, the use of EDDS is an attractive option for application in municipal wastewater tertiary treatments.

Previous work with EDDS in real MWTP effluents has been promising, demonstrating that the use of Fe:EDDS at 0.1:0.2 mM concentration ratio can efficiently degrade emerging contaminants at neutral $\mathrm{pH}[26,27]$. However, a systematic study focusing on the effect of the common parameters affecting the photo-Fenton process applied at neutral $\mathrm{pH}$ and in the presence of EDDS has never been done.

The aim of this work is to better understand the effect of $\mathrm{pH}, \mathrm{H}_{2} \mathrm{O}_{2}$ and $\mathrm{Fe}$ :EDDS concentrations on various aspects of an EDDS-assisted photo-Fenton treatment of MWTP effluents spiked with five micro-contaminants by performing a central composite experimental design (CCD). Phenol, bisphenol A, sulfamethoxazole, carbamazepine and pyrimethanil were chosen so as to be representative of the spectrum of different classes of chemicals commonly found in municipal wastewater. Response surfaces were constructed for initial degradation rate, percentage of contaminants degraded, $\mathrm{H}_{2} \mathrm{O}_{2}$ efficiency and stability of soluble iron. Lab-scale and pilot-scale systems were compared and an approach
Table 1

Composition of the MWTP effluents used in this work.

\begin{tabular}{lc}
\hline Main parameters & Range \\
\hline Ions $\left(\mathrm{mg} \mathrm{L}^{-1}\right)$ & \\
$\mathrm{Cl}^{-}$ & $440-687$ \\
$\mathrm{NO}_{2}{ }^{-}$ & $3.5-4.0$ \\
$\mathrm{Br}^{-}$ & $3.0-3.5$ \\
$\mathrm{NO}_{3}{ }^{-}$ & $3.0-4.5$ \\
$\mathrm{SO}_{4}{ }^{2-}$ & $148-174$ \\
$\mathrm{Na}^{+}$ & $276-358$ \\
$\mathrm{NH}_{4}{ }^{+}$ & $19-50$ \\
$\mathrm{~K}^{+}$ & $26-35$ \\
$\mathrm{Mg}^{2+}$ & $63-89$ \\
$\mathrm{Ca}^{2+}$ & $78-114$ \\
Turbidity (NTU) & $8.5-9.0$ \\
$\mathrm{Conductivity}\left(\mathrm{mS} \mathrm{cm}^{-1}\right)$ & $1.9-2.1$ \\
$\mathrm{pH}$ & $7.6-7.8$ \\
$\mathrm{COD}\left(\mathrm{mg} \mathrm{L}^{-1}\right)$ & $60-62$ \\
$\mathrm{IC}\left(\mathrm{mg} \mathrm{L}^{-1}\right)$ & $80-102$ \\
$\mathrm{DOC}\left(\mathrm{mg} \mathrm{L}^{-1}\right)$ & $11-15$ \\
\hline
\end{tabular}

for determining operability regions of near-optimal performance was carried out.

\section{Materials and methods}

\subsection{Reagents}

Iron source $\mathrm{Fe}_{2}\left(\mathrm{SO}_{4}\right)_{3} \cdot \mathrm{H}_{2} \mathrm{O} \quad(75 \%$ purity) and (S,S)ethylenediamine- $\mathrm{N}, \mathrm{N}^{\prime}$-disuccinic acid trisodium salt solution (35\% w/v) were both provided by Sigma-Aldrich. Hydrogen peroxide (30\% w/v) was purchased from Pancreac. Sulfuric acid (96\%) and sodium hydroxide were obtained from J.T. Baker. Carbamazepine and bisphenol A were obtained from Sigma-Aldrich. Sulfamethoxazole from Fluka, phenol from Pancreac and pyrimethanil from Agrevo. Acetonitrile (ACN) for the UPLC mobile phase was HPLCgrade and provided by Sigma-Aldrich. Millex PVDF $0.45 \mu \mathrm{m}$ filters were used for the preparation of the UPLC samples. For dissolved organic carbon, dissolved iron and $\mathrm{H}_{2} \mathrm{O}_{2}$ analyses, Millipore Nylon $0.20 \mu \mathrm{m}$ were used.

\subsection{Municipal wastewater treatment plant effluent}

All experiments were conducted in actual wastewater collected from the El Ejido (Almería, Spain) municipal wastewater treatment plant (MWTP), downstream of the secondary biological treatment. $\mathrm{H}_{2} \mathrm{SO}_{4}$ was used to strip $\mathrm{HCO}_{3}{ }^{-} / \mathrm{CO}_{3}{ }^{2-}$ (measured as inorganic carbon (IC)), until the final IC load was below $5 \mathrm{mg} \mathrm{L}^{-1}$ in order to avoid scavenger effect on hydroxyl radicals. Care was taken to significantly modify the natural water $\mathrm{pH}$. Wastewater collected from the experimental design was stored under refrigeration $\left(4-6{ }^{\circ} \mathrm{C}\right)$ and used within 10 days. Treated effluent collected from the pilot-scale experiments was used within 3 days. Some important physicochemical characteristics have been measured and can be seen in Table 1.

\subsection{Analytical setup}

The mixture of contaminants was prepared and stored in pure methanol, at a concentration of $1500 \mathrm{mg} \mathrm{L}^{-1}$ each as the parent solution. When the contaminants were added to the effluent, a small amount of DOC from methanol $\left(20 \mathrm{mg} \mathrm{L}^{-1}\right)$ was also introduced. An analytical method for Ultra Performance Liquid Chromatography (UPLC) has been developed. A Zorbax XDB-C18 column $(4.6 \times 50 \mathrm{~mm}$, particle size $1.8 \mu)$ was used. A linear gradient of $25 \mathrm{mM}$ formic acid/ACN solutions was used, progressing from $80 / 20$ to $0 / 100$ in $8 \mathrm{~min}$. Post time for subsequent equilibration was $4 \mathrm{~min}$. The flow rate was $1 \mathrm{~mL} \mathrm{~min}^{-1}$. UPLC samples were prepared 
by filtering $8 \mathrm{~mL}$ of solution through a $0.45 \mu \mathrm{m}$ PVDF syringe-driven filter, subsequently washed with $2 \mathrm{~mL}$ of $\mathrm{ACN}$ to verify total elution of the contaminants. The injected volume for all samples was $100 \mu \mathrm{L}$. The UV signal for each compound was recorded at the wavelength of maximum absorption (213 for phenol, 269 for carbamazepine, sulfamethoxazole and pyrimethanil, 280 for bisphenol A). Limits of detection (LOD) ranged from 1 to $7 \mu \mathrm{g} \mathrm{L}^{-1}$, while limits of quantification (LOQ) ranged from 1.5 to $15 \mu \mathrm{g} \mathrm{L}^{-1}$, depending on the contaminant. Concentrations were calculated using a 5point calibration curve $\left(5,10,25,50\right.$ and $\left.100 \mu \mathrm{g} \mathrm{L}^{-1}\right)$. Dissolved organic carbon (DOC) was measured by a Shimadzu TOC-V $\mathrm{V}_{\text {CSN }}$ analyzer equipped with an ASI-V automatic sampler. Fe:EDDS complexes were prepared daily prior to the experiments by adding $\mathrm{Fe}_{2}\left(\mathrm{SO}_{4}\right)_{3}$ in $50 \mathrm{~mL}$ distilled water acidified at $\mathrm{pH} 3$ and adding EDDS solution. Hydrogen peroxide concentrations were measured spectrophotometrically, by adding $0.5 \mathrm{~mL}$ of Titanium (IV) oxysulfate solution to $5 \mathrm{~mL}$ of sample and measuring absorbance at $410 \mathrm{~nm}$ (DIN 38402H15). Total dissolved iron concentration was measured by complexation with 1,10-phenanthroline and measuring absorbance at $510 \mathrm{~nm}$ (ISO 6332). All spectrophotometric measurements were made with a UNICAM UV/VIS spectrophotometer controlled with VISION software.

\subsection{Experimental set-up and procedure}

Experimental design was conducted in an Atlas XLS suntest solar simulator under constant illumination from a Xenon Lamp with an average UV irradiance of $30 \mathrm{~W} \mathrm{~m}^{-2}$ (typical solar UV power during a sunny day). A cylindrical Pyrex glass vessel (height $8.5 \mathrm{~cm}$, diameter $19 \mathrm{~cm}$, wall thickness $3.2 \mathrm{~mm}$ ) was filled with the MWTP effluent spiked with $100 \mu \mathrm{g} \mathrm{L}^{-1}$ of each of the five contaminants ( $500 \mu \mathrm{g} \mathrm{L}^{-1}$ of contaminants total) and the Fe:EDDS solution to a final volume of $1.5 \mathrm{~L}$. This volume corresponds to a height of $5 \mathrm{~cm}$ in this vessel, deliberately chosen so as to be the same as the diameter of a CPC tube. The sides of the pyrex vessel were covered so that light could only penetrate to the upper surface $\left(0.025 \mathrm{~m}^{2}\right.$ of illuminated area). UV radiation was monitored throughout the process with a SOLARLIGHT PMA2100 radiometer placed within the simulator. The $\mathrm{pH}$ was fixed to the desired level with $0.1 \mathrm{M}$ solutions of $\mathrm{NaOH}$ or $\mathrm{H}_{2} \mathrm{SO}_{4} \cdot \mathrm{H}_{2} \mathrm{O}_{2}$ was added and the simulator was sealed. Samples were taken every 5 min without disrupting the operation via a tube fixed to the vessel walls. The duration of each experiment was $60 \mathrm{~min}$. pH was followed with a portable CRISON pH meter. Temperature was measured with a HANNA portable water resistant thermometer. All experiments were conducted at initial solution temperatures of $22^{\circ} \mathrm{C}$. Application of air cooling kept it below $29^{\circ} \mathrm{C}$ during the course of the experiments.

Pilot scale experiments were conducted in a mobile CPC plant. The photocatalytic reactor was comprised of 20 borosilicate tubes (50 mm internal diameter, $1.5 \mathrm{~m}$ length, $2.5 \mathrm{~mm}$ thickness) and CРC mirrors of anodized aluminum. The plant was tilted $37^{\circ}$, equal to the local latitude (Tabernas, Almeria, Spain). Volume of each batch was $60 \mathrm{~L}$, with an illuminated volume of $45 \mathrm{~L}$ and a total illuminated area of $4.5 \mathrm{~m}^{2}$. Temperature and $\mathrm{pH}$ were monitored by probes inserted in the pipes. In all experiments the temperature never deviated from the $24-28^{\circ} \mathrm{C}$ range, so its effect is assumed negligible. Wastewater was introduced into a recirculation tank then pumped into the tubes with a flow of $29 \mathrm{~L} \mathrm{~min}^{-1}$ by using a centrifugal pump. Contaminants and Fe:EDDS were added and the $\mathrm{pH}$ was fixed with $2 \mathrm{M}$ solutions of $\mathrm{H}_{2} \mathrm{SO}_{4} / \mathrm{NaOH}$. $\mathrm{H}_{2} \mathrm{O}_{2}$ was then added and the system was left to recirculate. Solar photo-Fenton was initiated by uncovering the tubes and samples were taken every $5 \mathrm{~min}$.

Accumulated energy (Eq. (1)) was used instead of treatment time in order to have a normalized value for comparing the efficiency between the two reactors of different size and geometry, including variations of solar irradiation during scaling-up experiments in the CPC pilot plant.

$Q_{\mathrm{UV}, n+1}=Q_{\mathrm{UV}}+\Delta t_{n} \cdot \overline{\mathrm{UV}}_{G, n+1} \cdot \frac{A_{\mathrm{i}}}{V_{\mathrm{T}}}$

$\Delta t_{n}=t_{n+1}-t_{n}$

where $Q_{U V}\left(\mathrm{~kJ} \mathrm{~L}^{-1}\right)$ is the accumulated UV energy per unit of volume, $\mathrm{UV}_{G, n+1}\left(\mathrm{~W} \mathrm{~m}^{-2}\right)$ is the average solar ultraviolet radiation $(\lambda<400 \mathrm{~nm})$ measured between $t_{n+1}$ and $t_{n}$ and $A_{i}$ is the illuminated area $\left(\mathrm{m}^{2}\right) . V_{\mathrm{T}}(\mathrm{L})$ is the total volume of the reactor.

\subsection{Central composite design}

Response surface methodology (RSM) is a set of mathematical and statistical techniques widely used for analyzing engineering problems dependent on several variables. Central composite designs are among the most popular RSM methods, allowing for estimation of curvature along the response surface via the inclusion of quadratic terms. In this work, the chosen region of interest for each variable selected was between 0.025 and $0.25 \mathrm{mM}$ for $\left[\mathrm{Fe}^{3+}\right]$ (Fe:EDDS always maintained at 1:2 ratio), $\left[\mathrm{H}_{2} \mathrm{O}_{2}\right]$ between 30 and $100 \mathrm{mg} \mathrm{L}^{-1}$ and $\mathrm{pH}$ between 5 and 8 . Previous work has shown that 0.1:0.2 mM of Fe:EDDS has been sufficient for treating concentrations from 60 to $1500 \mu \mathrm{gL}^{-1}$ of total contaminants in MWTP effluent with a $\mathrm{H}_{2} \mathrm{O}_{2}$ consumptions between 30 and $90 \mathrm{mg} \mathrm{L}^{-1}$ [28]. The range of concentrations was chosen on the basis of these results. The choice of maintaining the molar ratio at 1:2 was made because it has been demonstrated to be favorable to $1: 1$ in terms of degradation rate and $\mathrm{H}_{2} \mathrm{O}_{2}$ consumption for the treatment of pharmaceuticals in MWTP effluent $[27,28]$. Higher ratios were not used in order to limit the increase of DOC due to the addition of EDDS. A rotatable central composite design with an alpha value of 1.682 would require experimentation at inadmissible negative values of $\mathrm{Fe}^{3+}$ concentration and $\mathrm{pH}$ values well beyond the typical ones found in real wastewater. In light of this limitation, a face-centered central composite design (FCD) was used instead, which is advisable whenever the regions of interest and operability coincide [29].

The experimental matrix found in Table 2 summarizes the performed runs. Minitab statistical software was used for analysis of the design and plotting of the response surfaces. Depiction of the response surfaces was made by holding one of the variables constant at the center point ( 5 for $\mathrm{pH}, 0.1375 \mathrm{mM}$ for $\left[\mathrm{Fe}^{3+}\right]$ and $65 \mathrm{mg} \mathrm{L}^{-1}$ for $\left[\mathrm{H}_{2} \mathrm{O}_{2}\right]$ ) and plotting the response as a function of the other two. A set of three graphs was generated for each response. Different responses have been selected in this study as it is explained below.

\section{Results and discussion}

When conducting an experimental design for an applied engineering problem, it can be worthwhile to explore multiple response factors. In this way, the effect of the operational variables on several aspects of the process can be evaluated. In this work, the following response factors have been studied, presented here along with their corresponding model equations (Eqs. (2)-(5)). Corresponding ANOVA tables for each model equation are presented in Table 3. Only the terms with $P<0.1$ (90\% level of significance) have been used for the construction of the model equations.

1) Initial degradation rate (in terms of $\mu \mathrm{g} \mathrm{L}^{-1}$ of contaminant removed per kJ of $\mathrm{UV}$ radiation received $R^{2}=0.9521, F$ value of 
Table 2

Experimental design matrix with each of the acquired responses $\left(R^{2}>0.990\right.$ for the initial degradation rates used for the calculation of $\left.y_{1}\right)$.

\begin{tabular}{|c|c|c|c|c|c|c|c|c|}
\hline Standard order & Run order & $\mathrm{pH}$ & $\mathrm{Fe}(\mathrm{mM})$ & $\mathrm{H}_{2} \mathrm{O}_{2}\left(\mathrm{mg} \mathrm{L}^{-1}\right)$ & $y_{1}\left(\mu \mathrm{gkJ}^{-1}\right)$ & $y_{2}(\%)$ & $y_{3}(\mu \mathrm{g} / \mathrm{mg})$ & $y_{4}(\%)$ \\
\hline 1 & 17 & 5.0 & 0.0250 & 30 & 195 & 31 & 4.2 & 22 \\
\hline 2 & 4 & 8.0 & 0.0250 & 30 & 106 & 19 & 2.6 & 6 \\
\hline 3 & 6 & 5.0 & 0.2500 & 100 & 1561 & 95 & 14.4 & 93 \\
\hline 4 & 20 & 8.0 & 0.2500 & 30 & 610 & 67 & 8.1 & 91 \\
\hline 5 & 14 & 5.0 & 0.0250 & 100 & 320 & 39 & 9.7 & 40 \\
\hline 6 & 15 & 8.0 & 0.0250 & 100 & 118 & 17 & 2.0 & 5 \\
\hline 7 & 18 & 5.0 & 0.2500 & 30 & 1283 & 80 & 11 & 90 \\
\hline 8 & 3 & 8.0 & 0.2500 & 100 & 1230 & 93 & 6.6 & 75 \\
\hline 9 & 8 & 5.0 & 0.1375 & 65 & 929 & 85 & 8.9 & 34 \\
\hline 10 & 10 & 8.0 & 0.1375 & 65 & 464 & 70 & 4.8 & 40 \\
\hline 11 & 7 & 6.5 & 0.0250 & 65 & 208 & 25 & 4.8 & 7 \\
\hline 12 & 9 & 6.5 & 0.2500 & 65 & 804 & 90 & 7.2 & 92 \\
\hline 13 & 11 & 6.5 & 0.1375 & 30 & 811 & 73 & 11.4 & 52 \\
\hline 14 & 13 & 6.5 & 0.1375 & 100 & 826 & 92 & 9.6 & 30 \\
\hline 15 & 2 & 6.5 & 0.1375 & 65 & 770 & 81 & 10.2 & 47 \\
\hline 16 & 1 & 6.5 & 0.1375 & 65 & 801 & 79 & 9.9 & 49 \\
\hline 17 & 5 & 6.5 & 0.1375 & 65 & 829 & 80 & 10.2 & 51 \\
\hline 18 & 16 & 6.5 & 0.1375 & 65 & 814 & 80 & 11.4 & 48 \\
\hline 19 & 12 & 6.5 & 0.1375 & 65 & 799 & 81 & 11.2 & 45 \\
\hline 20 & 19 & 6.5 & 0.1375 & 65 & 819 & 82 & 10.4 & 48 \\
\hline
\end{tabular}

model $=43.49)$ :

$$
\begin{aligned}
y_{1} & =-279+163 \mathrm{pH}+13096 \mathrm{Fe}-6.86 \mathrm{H}_{2} \mathrm{O}_{2}-17304(\mathrm{Fe})^{2} \\
& +0.08\left(\mathrm{H}_{2} \mathrm{O}_{2}\right)^{2}-830 \mathrm{pH} \times \mathrm{Fe}
\end{aligned}
$$

2) Percentage of the sum of micro contaminants removed by the time the degradation process slows down $\left(R^{2}=0.9852, F\right.$ value of model $=136.51$ ):

$$
\begin{aligned}
y_{2} & =-10.60+13.51 \mathrm{pH}+598.54 \mathrm{Fe}-0.14 \mathrm{H}_{2} \mathrm{O}_{2}-1850(\mathrm{Fe})^{2} \\
& -14.8 \mathrm{pH} \times \mathrm{Fe}+1.1 \mathrm{Fe} \times \mathrm{H}_{2} \mathrm{O}_{2}
\end{aligned}
$$

3) Efficiency of hydrogen peroxide consumption (in terms of $\mu \mathrm{g}^{-1}$ of contaminant eliminated per $\mathrm{mg} \mathrm{L}^{-1}$ of $\mathrm{H}_{2} \mathrm{O}_{2}$ consumed, $R^{2}=0.9054, F$ value of model $=11.89$ ):

$$
y_{3}=-26.21+11 \mathrm{pH}+90.2 \mathrm{Fe}-0.93(\mathrm{pH})^{2}-0.36 \mathrm{Fe} \times \mathrm{H}_{2} \mathrm{O}_{2}
$$

4) Percentage of total dissolved iron in solution by the end of the process $\left(R^{2}=0.9686, F\right.$ value of model $\left.=33.64\right)$ :

$y_{4}=-40.52+19.80 \mathrm{pH}+78 \mathrm{Fe}+0.18 \mathrm{H}_{2} \mathrm{O}_{2}+593(\mathrm{Fe})^{2}$

\subsection{Initial degradation rate $\left(\mathrm{r}_{0}\right)$ and percentage of degradation achieved}

In Fig. 1 the response surfaces obtained for the two first response factors $\left(y_{1}\right.$ and $\left.y_{2}\right)$ considered in this work are shown.

The Fe(III)-EDDS complex, if kept in the dark, is stable in the entirety of the 5-8 pH region. Due to the stability of the complex, iron is not initially available for participating in homogeneous Fenton reactions. No contaminant degradation was therefore observed in the dark, it was not available for participation in homogeneous Fenton reactions. Under illumination, the complex is rapidly photodegraded and the iron consequently liberated. Complete photodegradation of $0.1 \mathrm{mM}$ of $\mathrm{Fe}$ (III)-EDDS has been reported to occur within only $12 \mathrm{~min}$ of UV-vis light $(300 \mathrm{~nm}<\lambda<500 \mathrm{~nm})$ irradiation [30]. The low degradation efficiency observed when 0.025:0.05 mM of Fe:EDDS were used is indicative of the loss of iron from the solution. Higher Fe:EDDS concentrations would be more successful.

Initial degradation rate exhibits a downward trend between $\mathrm{pH}$ 5 and 8, regardless of $\mathrm{H}_{2} \mathrm{O}_{2}$ concentration. This behavior appears contrary to what has appeared in the literature (in demineralized water), where higher $\mathrm{pH}$ leads to higher initial rates when EDDS complex agent is used [31]. There are several effects which can occur within this $\mathrm{pH}$ range: first, at higher $\mathrm{pH}$, superoxide radical anion $\left(\mathrm{O}_{2}{ }^{-}-\right)$is present in higher quantities and contributes to the direction of the $\mathrm{Fe}(\mathrm{II}) / \mathrm{Fe}(\mathrm{III})$ equilibrium toward $\mathrm{Fe}(\mathrm{II})$ formation. Second, starting from $\mathrm{pH} 7$ upwards, the speciation of Fe(III)/EDDS complexes begins to differ, with the form $\mathrm{FeL}^{-}$decreasing and $\mathrm{FeOHL}^{2-}$ becoming more dominant. At $\mathrm{pH} 8$, it is suggested [30] that the two species are present in almost equal concentrations. As the $\mathrm{FeOHL}^{2-}$ form is suggested to be less photochemically efficient [30], it could contribute to the decrease in degradation rate. Third, the quantum yield of $\mathrm{HO}^{\bullet}$ formation from the photolysis of $\mathrm{Fe}(\mathrm{III})$-EDDS increases at higher $\mathrm{pH}$ [31] (contrary to what happens with citrate, oxalate and $\mathrm{Fe}$ (III)-aqua complexes, whose quantum yield becomes negligible around $\mathrm{pH} 7$ [32]). Fourth, the iron released once the Fe(III)-EDDS complex begins to photolyse would be expected to precipitate faster at higher $\mathrm{pH}$, hindering the degradation. The fact that the initial rate is lower with increasing $\mathrm{pH}$ may mean that the equilibrium of these different elements in MWTP effluent is different than in demineralised water.

In addition, independently of the other two variables, there is not a significant influence of hydrogen peroxide on the initial degradation rate. As the entire range of $\mathrm{H}_{2} \mathrm{O}_{2}$ concentrations studied was about 2 orders of magnitude greater than of the contaminants, this result is not unexpected, especially given the complexity of the effluent.

Regarding the percentage of contaminants eliminated at the end of the process, it can be seen that at the lowest iron concentration $(0.025 \mathrm{mM})$, removal percentage is lower than $40 \%$, regardless of the combination of the other two variables. It could be argued however that the limiting step is the rapid photodegradation of the Fe(III):EDDS complex. The relatively low concentration of excess EDDS $(0.05 \mathrm{mM}$ total) recomplexes the iron in solution, but is depleted before complete degradation can be achieved. Studies conducted with varying ratios of Fe to EDDS have shown [33] that iron concentrations as low as $0.01 \mathrm{mM}$ can be maintained in solution and contribute to contaminant degradation, provided EDDS is found in abundance $(0.25 \mathrm{mM})$.

The influence of the $\mathrm{pH}$ on the percentage of contaminants degraded is relatively minimal throughout the whole region of interest. High $\mathrm{pH}$ may negatively affect the kinetics of the degradation, but the end-point nevertheless remains the same. This observed stability could be attributed, as mentioned above, 

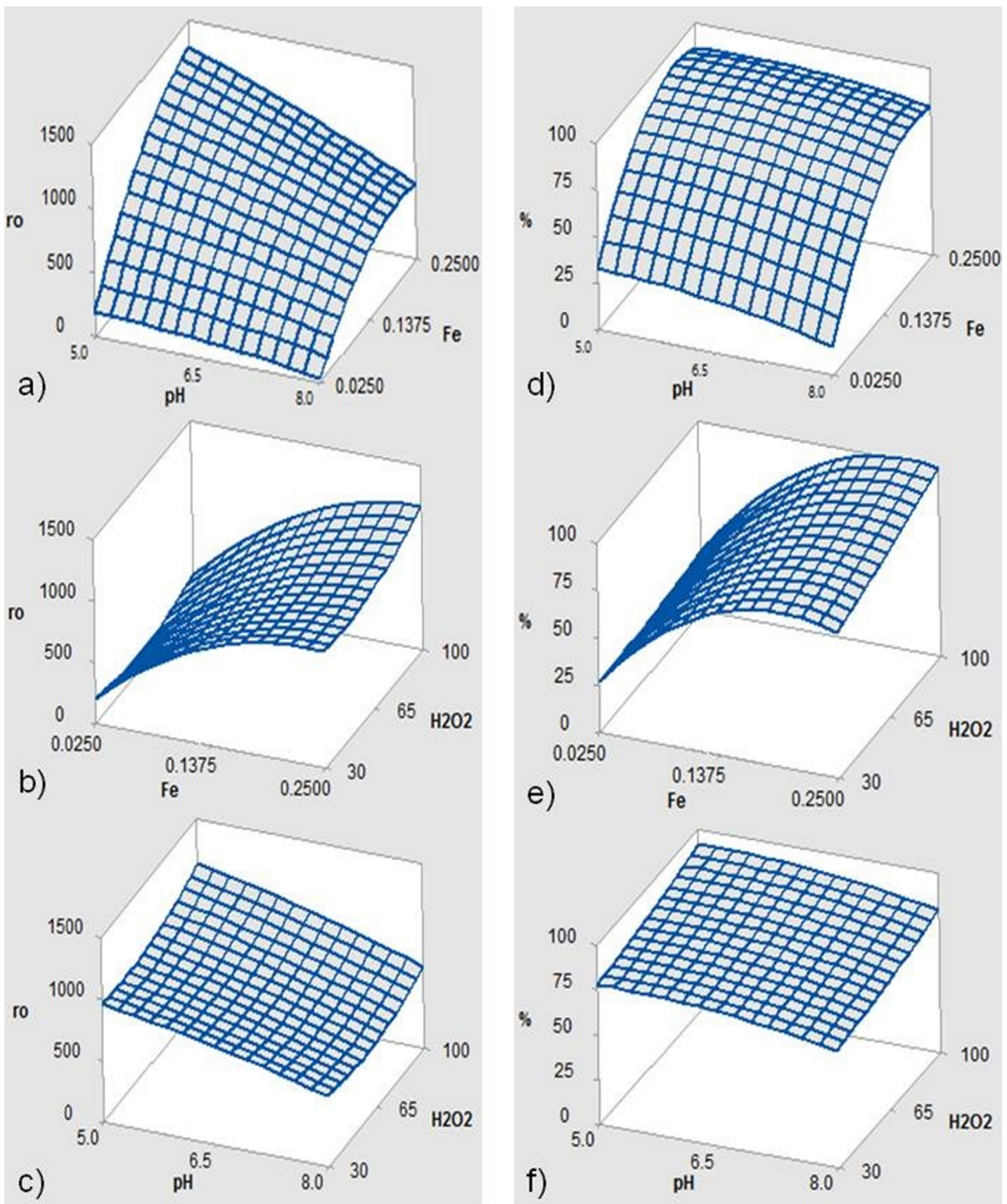

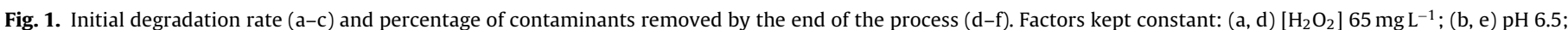
(c, f) [Fe:EDDS] 0.1375:0.275 mM.

to the competing tendencies at higher $\mathrm{pH}$ between faster iron precipitation and higher quantum yield. Even though $30 \mathrm{mg} \mathrm{L}^{-1}$ of $\mathrm{H}_{2} \mathrm{O}_{2}$ are successful in removing about $70-75 \%$ of contaminants under all conditions, removal of $90 \%$ and above requires addition of $\mathrm{H}_{2} \mathrm{O}_{2}$ concentrations above $65 \mathrm{mg} \mathrm{L}^{-1}$.

\section{2. $\mathrm{H}_{2} \mathrm{O}_{2}$ consumption efficiency $\left(\mathrm{R}_{p}\right)$ and iron availability}

In Fig. 2 the response surfaces obtained for the third and fourth response factors $\left(y_{3}\right.$ and $\left.y_{4}\right)$ are shown.

$\mathrm{H}_{2} \mathrm{O}_{2}$ consumption efficiency $\left(R_{\mathrm{p}}=\mu \mathrm{g}\right.$ contaminant $/ \mathrm{mg} \mathrm{H}_{2} \mathrm{O}_{2}$ consumed) is exceptionally low at the lowest iron concentrations (Fig. 2( $a$ and $b$ )). As the concentration of EDDS is also low, its complete photodegradation occurs within a few minutes. The medium is almost immediately deprived of the decomplexed iron due to its fast precipitation (faster at higher $\mathrm{pH}$ values, Fig. 2(a)). In the absence of iron, it is probable that $\mathrm{H}_{2} \mathrm{O}_{2}$ is being consumed while reacting with the less recalcitrant natural organic compounds present in the wastewater.

Higher iron concentration allows for better $\mathrm{H}_{2} \mathrm{O}_{2}$ consumption, regardless of initial $\mathrm{H}_{2} \mathrm{O}_{2}$ concentration, and near-optimal values are clearly observed around $0.1375 \mathrm{mM}$.

Maintaining iron in solution is one of the most significant challenges when working at neutral $\mathrm{pH}$. Therefore, it was of interest to observe its stability in the studied region. Fig. 2(d-f), displays the response surfaces of the percentage of iron remaining in solution after 60 min of simulated solar irradiation. Given the constant lamp radiation of $30 \mathrm{~W} \mathrm{~m}^{-2}$ of UVA, this corresponds to an accumulated UVA energy of $2.04 \mathrm{~kJ} \mathrm{~L}^{-1}$. As seen in Fig. 2(d and e), almost all of the iron was lost at the lowest concentrations. The percentage of 

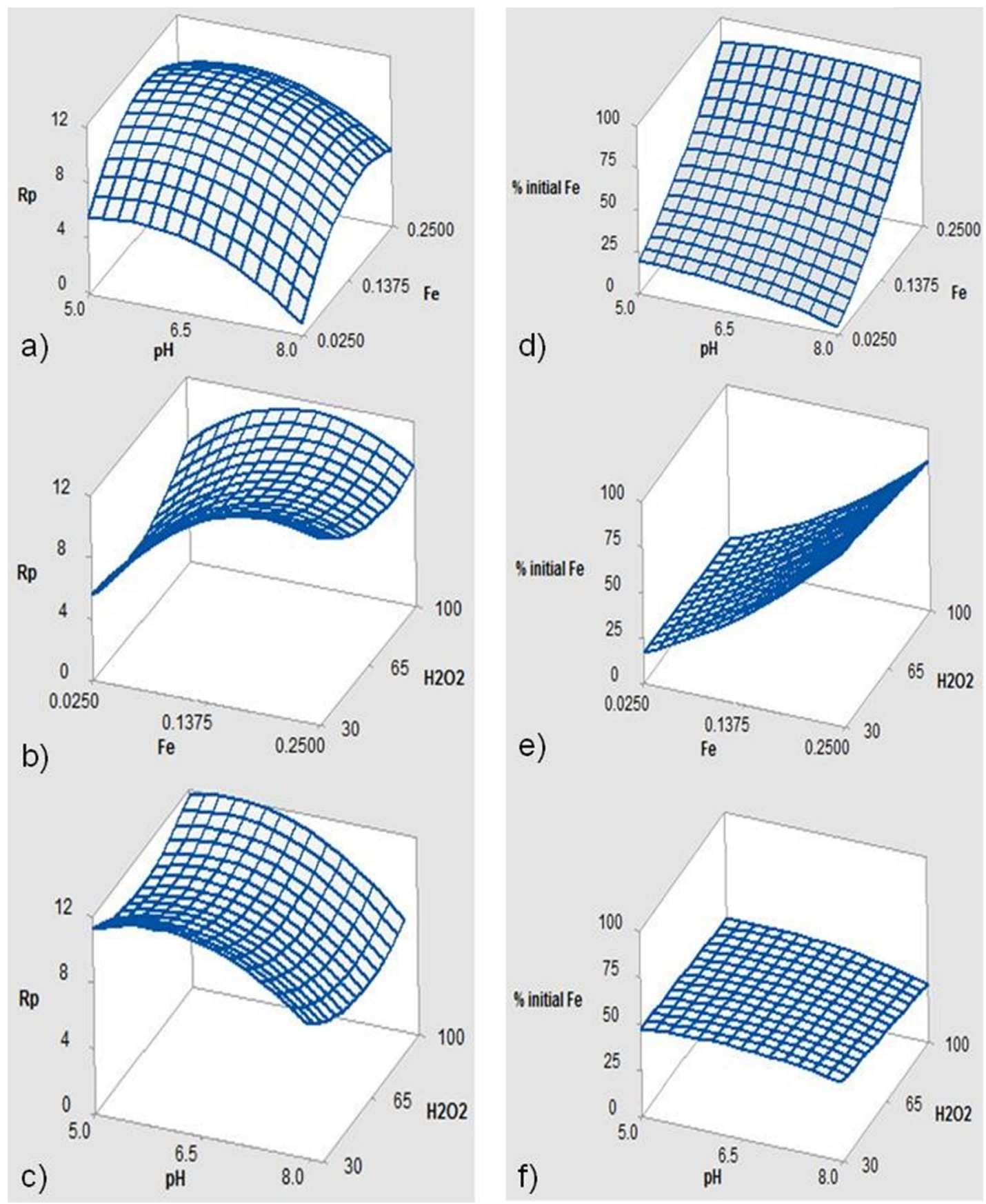

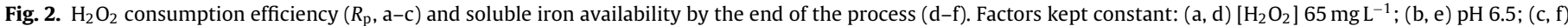
[Fe:EDDS] 0.1375:0.275 mM.

iron remaining in solution increased with higher initial Fe:EDDS concentrations, with almost no losses observed at the highest concentrations. It is mentioned in the literature that the ratio between $\mathrm{Fe}(\mathrm{III})$ and EDDS in $\mathrm{Fe}(\mathrm{III})$-EDDS species prevalent between $\mathrm{pH} 5$ and 8 is always 1:1 [30]. Additionally, Metsarinne et al. [34] mentioned that while Fe(III)-EDDS is rapidly photodegraded, EDDS alone can be stable for days in both distilled and more complex lake water. Uncomplexed EDDS can thus be expected to remain stable for the duration of the experiment. Following the initial photochemical reaction, oxidation of $\mathrm{Fe}(\mathrm{II})$ and complexation has been suggested to be possible when EDDS is found in excess [33], according to the following reactions (Reacts. 3 and 4).

$\mathrm{Fe}(\mathrm{III})-\mathrm{EDDS} \stackrel{h v}{\longrightarrow}[\mathrm{Fe}(\mathrm{III})-\mathrm{EDDS}] * \rightarrow \mathrm{Fe}(\mathrm{II})+\mathrm{EDDS}^{\bullet}$
$\left.\mathrm{Fe}(\mathrm{II})+\mathrm{EDDS}^{\mathrm{O}_{2}, \mathrm{H}_{2} \mathrm{O}_{2}} \longrightarrow \mathrm{Fe}(\mathrm{III})-\mathrm{EDDS}\right]$

It should be mentioned that the observed loss of iron was not gradual from the beginning of the experiment but would happen rapidly from the moment a certain amount of radiation had been received by the system. At the highest concentrations (around 0.25:0.5 mM of Fe:EDDS), no loss of iron was observed at all during the $60 \mathrm{~min}$ of the experiment. Given that Fe(III)-EDDS photolysis begins almost immediately and that any free iron would be expected to precipitate rapidly in the $5-8 \mathrm{pH}$ range, this delay seems to suggest that (React. 4) does indeed happen. The persistence of iron in solution at the highest Fe:EDDS concentrations also suggests that the complexation of free iron with excess EDDS was faster than its precipitation. In the case of medium concentrations, 
Table 3

ANOVA tables for the linear, quadratic and interaction terms of each of the four model equations $y_{1}(\mathrm{a}), y_{2}(\mathrm{~b}), y_{3}(\mathrm{c})$ and $y_{4}(\mathrm{~d})$.

\begin{tabular}{|c|c|c|c|c|c|}
\hline & DF & Adj SS & Adj MS & $F$-value & $P$-value \\
\hline \multicolumn{6}{|l|}{ a) } \\
\hline Model & 9 & 2583051 & 287006 & 42.5 & 0 \\
\hline Linear & 3 & 2220177 & 740059 & 110 & 0 \\
\hline $\mathrm{pH}$ & 1 & 469589 & 469589 & 69.5 & 0 \\
\hline $\mathrm{Fe}$ & 1 & 1709244 & 1709244 & 253 & 0 \\
\hline $\mathrm{H}_{2} \mathrm{O}_{2}$ & 1 & 41345 & 41345 & 6.1 & 0.033 \\
\hline Square & 3 & 186448 & 62149 & 9.2 & 0.003 \\
\hline $\mathrm{pH} \times \mathrm{pH}$ & 1 & 2259 & 2259 & 0.3 & 0.576 \\
\hline $\mathrm{Fe} \times \mathrm{Fe}$ & 1 & 131904 & 131904 & 19.5 & 0.001 \\
\hline $\mathrm{H}_{2} \mathrm{O}_{2} \times \mathrm{H}_{2} \mathrm{O}_{2}$ & 1 & 23959 & 23959 & 3.6 & 0.089 \\
\hline 2-Way interactions & 3 & 176425 & 58808 & 8.7 & 0.004 \\
\hline $\mathrm{pH} \times \mathrm{Fe}$ & 1 & 156800 & 156800 & 23.2 & 0.001 \\
\hline $\mathrm{pH} \times \mathrm{H}_{2} \mathrm{O}_{2}$ & 1 & 3961 & 3961 & 0.59 & 0.462 \\
\hline $\mathrm{Fe} \times \mathrm{H}_{2} \mathrm{O}_{2}$ & 1 & 15664 & 15664 & 2.32 & 0.159 \\
\hline \multicolumn{6}{|l|}{ b) } \\
\hline Model & 9 & 12676.2 & 1408.5 & 136.1 & 0 \\
\hline Linear & 3 & 9430.7 & 3143.6 & 303.6 & 0 \\
\hline $\mathrm{pH}$ & 1 & 396.9 & 396.9 & 38.3 & 0 \\
\hline $\mathrm{Fe}$ & 1 & 8584.9 & 8585.9 & 829.2 & 0 \\
\hline $\mathrm{H}_{2} \mathrm{O}_{2}$ & 1 & 448.9 & 449.9 & 43.4 & 0 \\
\hline Square & 3 & 3033.5 & 1011.2 & 97.7 & 0 \\
\hline $\mathrm{pH} \times \mathrm{pH}$ & 1 & 32 & 32 & 3.1 & 0.109 \\
\hline $\mathrm{Fe} \times \mathrm{Fe}$ & 1 & 150 & 1507 & 145.6 & 0 \\
\hline $\mathrm{H}_{2} \mathrm{O}_{2} \times \mathrm{H}_{2} \mathrm{O}_{2}$ & 1 & 7 & 7 & 0.7 & 0.431 \\
\hline 2-Way interactions & 3 & 212 & 70.7 & 6.8 & 0.009 \\
\hline $\mathrm{pH} \times \mathrm{Fe}$ & 1 & 50 & 50 & 4.8 & 0.053 \\
\hline $\mathrm{pH} \times \mathrm{H}_{2} \mathrm{O}_{2}$ & 1 & 0 & 0 & 0 & 1 \\
\hline \multirow{2}{*}{\multicolumn{6}{|c|}{ c) }} \\
\hline & & & & & \\
\hline Model & 9 & 162 & 18 & 7.5 & 0.002 \\
\hline Linear & 3 & 79.3 & 26 & 11 & 0.002 \\
\hline $\mathrm{pH}$ & 1 & 39.5 & 39 & 16.6 & 0.002 \\
\hline $\mathrm{Fe}$ & 1 & 39.1 & 39 & 16.4 & 0.002 \\
\hline $\mathrm{H}_{2} \mathrm{O}_{2}$ & 1 & 0.6 & 0.6 & 0.3 & 0.627 \\
\hline Square & 3 & 66.2 & 22.1 & 9.2 & 0.003 \\
\hline $\mathrm{pH} \times \mathrm{pH}$ & 1 & 11.9 & 11.9 & 5 & 0.049 \\
\hline $\mathrm{Fe} \times \mathrm{Fe}$ & 1 & 23.5 & 23.5 & 9.8 & 0.011 \\
\hline $\mathrm{H}_{2} \mathrm{O}_{2} \times \mathrm{H}_{2} \mathrm{O}_{2}$ & 1 & 6.8 & 6.8 & 2.9 & 0.122 \\
\hline 2-Way interactions & 3 & 16.5 & 5.5 & 2.3 & 0.139 \\
\hline $\mathrm{pH} \times \mathrm{Fe}$ & 1 & 0.9 & 0.9 & 0.4 & 0.555 \\
\hline $\mathrm{pH} \times \mathrm{H}_{2} \mathrm{O}_{2}$ & 1 & 1.6 & 1.6 & 0.6 & 0.438 \\
\hline $\mathrm{Fe} \times \mathrm{H}_{2} \mathrm{O}_{2}$ & 1 & 14.1 & 14.1 & 5.9 & 0.036 \\
\hline \multicolumn{6}{|l|}{ d) } \\
\hline Model & 9 & 13929.4 & 1547.7 & 33.6 & 0 \\
\hline Linear & 3 & 13569.8 & 4523.3 & 98.1 & 0 \\
\hline $\mathrm{pH}$ & 1 & 152.1 & 152.1 & 3.3 & 0.099 \\
\hline $\mathrm{Fe}$ & 1 & 13249.6 & 13249.6 & 287.3 & 0 \\
\hline $\mathrm{H}_{2} \mathrm{O}_{2}$ & 1 & 168.1 & 168.1 & 3.6 & 0.085 \\
\hline Square & 3 & 181.3 & 60.4 & 1.3 & 0.325 \\
\hline $\mathrm{pH} \times \mathrm{pH}$ & 1 & 44 & 44 & 0.9 & 0.352 \\
\hline $\mathrm{Fe} \times \mathrm{Fe}$ & 1 & 154.7 & 154.7 & 3.3 & 0.097 \\
\hline $\mathrm{H}_{2} \mathrm{O}_{2} \times \mathrm{H}_{2} \mathrm{O}_{2}$ & 1 & 0 & 0 & 0 & 1 \\
\hline 2-Way interactions & 3 & 178.4 & 59.5 & 1.3 & 0.331 \\
\hline $\mathrm{pH} \times \mathrm{Fe}$ & 1 & 91.1 & 91.1 & 2 & 0.19 \\
\hline $\mathrm{pH} \times \mathrm{H}_{2} \mathrm{O}_{2}$ & 1 & 21.1 & 21.1 & 0.5 & 0.514 \\
\hline $\mathrm{Fe} \times \mathrm{H}_{2} \mathrm{O}_{2}$ & 1 & 66.1 & 66.1 & 1.4 & 0.259 \\
\hline
\end{tabular}

the observed behavior means that only part of the excess EDDS was photodegraded within the time of the experiment and was available for complexing more iron through (React. 4).

Effects of $\mathrm{pH}$ and $\mathrm{H}_{2} \mathrm{O}_{2}$ on the percentage of iron retained in solution are minimal, although the curvature observed around $\mathrm{pH}$ 6.5 seems to be in accordance with Metsarinne et al. [34], who have observed higher stability of Fe(III)-EDDS at pH 6.5 both in distilled and lake water.

\subsection{Scale-up to a CPC solar photo-reactor at pilot plant scale}

In order to verify the general applicability of the results obtained in the solar simulator, a set of three conditions has been tested in a $60 \mathrm{~L}$ CPC photo-reactor under solar light.

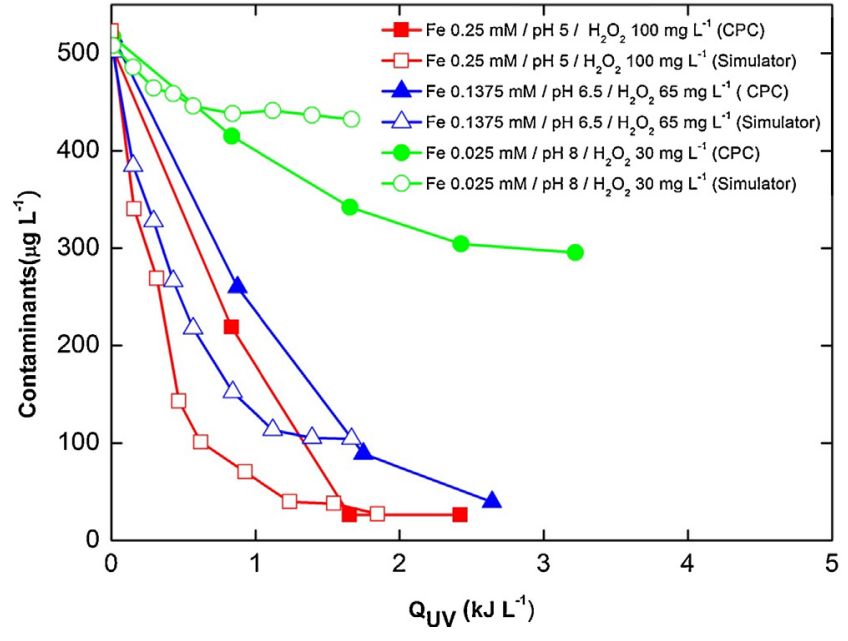

Fig. 3. Cross-scale comparison between the degradation performance on the $1.5 \mathrm{~L}$ photo-reactor under simulated solar radiation and using $60 \mathrm{~L}$ solar CPC pilot plant.

The rate of energy accumulation in the CPC tubes was higher than in the solar simulated system considering an average radiation of $30 \mathrm{~W} \mathrm{~m}^{-2}$ (about $0.17 \mathrm{~kJ} \mathrm{~min}^{-1} \mathrm{~L}^{-1}$ in the CPC compared to $0.03 \mathrm{~kJ} \mathrm{~min}^{-1} \mathrm{~L}^{-1}$ in the simulator), so the process was significantly faster. 90\% degradation was reached in $35 \mathrm{~min}$ in the simulated system, while the same percentage was reached in the CPC in less than $10 \mathrm{~min}$. As can be seen in Fig. 3, there is a good degree of correlation between the two systems despite the different timeframes. This correlation emphasizes the importance of UV energy density on degradation kinetics, independently of reaction volume. At low concentrations of Fe:EDDS the correlation was not adequate, as the system was most seriously affected by the loss of iron. As commented before, Fe (III)-EDDS photolysis begins almost immediately, releasing free iron that is expected to precipitate rapidly in the $5-8 \mathrm{pH}$ range. The released iron cannot remain in solution for as long as required by the slower treatment in the solar simulator (as incident radiation per minute and liter was lower), so the process is hindered more seriously than in the CPC. This reinforces the idea that solar photo-reactors should be designed to profit the most of solar irradiation absorbance, maximizing illuminated volume/total volume ratio.

\subsection{Desirability function approach for multiple response process optimization}

When discussing optimization, it should be preferable to take into account more than one aspect of the process, seeking instead a compromise for achieving efficiency across multiple responses. This approach can help in defining regions of near-optimal performance. As there is a high degree of correlation in terms of accumulated $Q_{U V}$ between the two systems, the experimental design results could be applied even in the context of multiplemodule CPC reactor systems. In this case, the objective should be a set of condition achieving high initial degradation rate $\left(y_{1}\right)$, complete contaminants removal $\left(y_{2}\right)$ and high $\mathrm{H}_{2} \mathrm{O}_{2}$ consumption efficiency $\left(y_{3}\right)$. A common strategy used within the response surface framework is the desirability function approach, consisting of converting the multiple responses into a single composite function [35]. For each of the three responses $y_{1}, y_{2}, y_{3}$, individual desirability functions $\left(d_{i}\right)$ are defined according to Eq. (6). It can obtain values between 0 and 1 , with maximum desirability obtained at the 


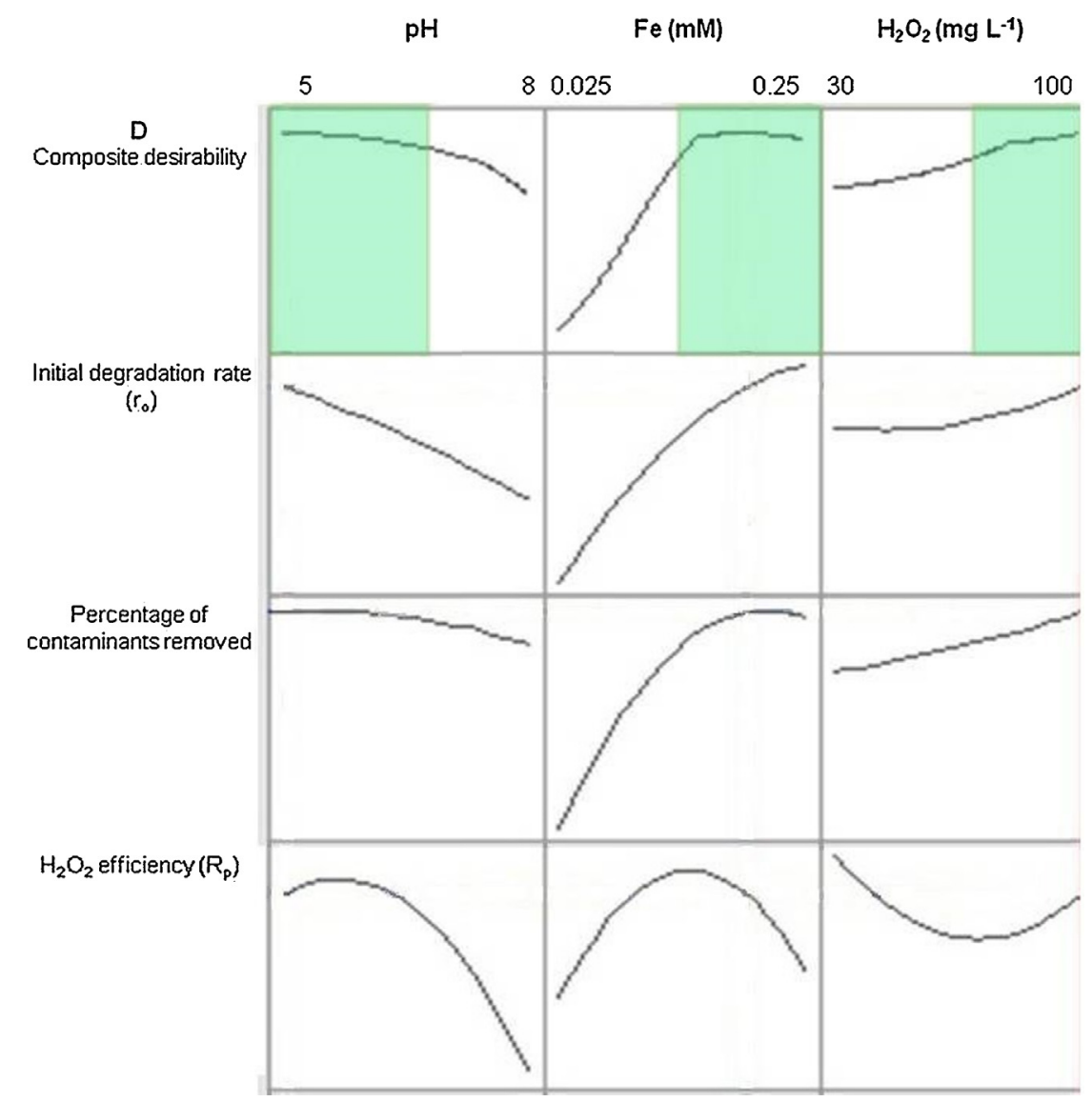

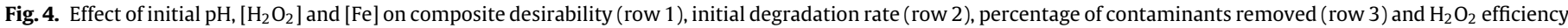
(row 4).

maximum response.

$d_{i}=\left\{\begin{array}{l}0 \quad y \leq y_{\min } \\ \left(\frac{y-y_{\min }}{y_{\max }-y_{\min }}\right)^{W_{i}} \\ 1 \quad y \geq y_{\max }\end{array}\right.$

The parameter $W_{\mathrm{i}}$ represents a weight which defines the shape of the function. Large weights signify a sharp increase in $d_{\mathrm{i}}$ only when $y_{\mathrm{i}}$ is close to $y_{\max }$. Consequently, if one of the responses has higher importance for a given optimization objective, setting a high $W_{\mathrm{i}}$ limits the acceptable range to a region very near the maximum. As reaching complete contaminant removal is the most important objective, the corresponding $W_{2}$ has been set higher than both $W_{1}$ and $W_{3} . W_{1}$ and $W_{3}$ have been set to 1 , while $W_{2}$ has been set to 2 .

An aggregate composite desirability function $D$ is constructed by calculating the weighted geometric mean of the three individual desirabilities.

$D=\sqrt[3]{d_{1}{ }^{w_{1}} \times d_{2}{ }^{w_{2}} \times d_{3}{ }^{w_{3}}}$

Each column of the plot shown in Fig. 4 displays the influence of each factor on the composite desirability D (row 1) and on each of the chosen responses (rows 2-4). Highlighted areas in Fig. 4 demonstrate acceptable operability conditions. In terms of process control, it could be said that $\mathrm{pH}$ would only have to be regulated when it strongly deviates toward high values. [Fe] should be around $0.2 \mathrm{mM}$, while $\left[\mathrm{H}_{2} \mathrm{O}_{2}\right]$ should be above $65-70 \mathrm{mg} \mathrm{L}^{-1}$ for maximum removal. The chosen weights are indicative, as this approach allows for flexible optimization objectives, depending on individual priorities.

\section{Conclusions}

This work has verified that treatment of micro-contaminants with the use of EDDS as an iron-complexing agent is possible in real wastewater effluent at a $\mathrm{pH}$ range between 5 and 8. Initial degradation rate decreases at higher $\mathrm{pH}$, but complete degradation is nevertheless achieved in the presence of sufficient Fe:EDDS concentrations. The fact that the contaminants are eliminated in the presence of relatively high DOC values (about 2 orders of magnitude greater) is especially promising.

The results obtained from the solar simulator provide a very good estimate of the behavior of the pilot-scale CPC solar photoreactor in terms of $Q_{U V}$. Due to the limited irradiated area of the reactor in the solar simulator, the process was significantly longer. In the CPC however, the amount of radiation necessary for achieving complete degradation was reached within just a few minutes.

A correlation has also been made between iron precipitation and accumulated UV radiation. Further research is definitely required but it could allow for an empirical estimation of optimal Fe:EDDS ratios with respect to different applications.

\section{References}

[1] R. Loos, R. Carvalho, D.C. Antonio, S. Comero, G. Locoro, S. Tavazzi, B. Paracchini, M. Ghiani, T. Lettieri, L. Blaha, B. Jarosova, S. Voorspoels, K. Servaes, P. Haglund, J. Fick, R.H. Lindberg, D. Schwesig, B.M. Gawlik, Water Res. 47 (2013) 6475-6487.

[2] B. Petrie, R. Barden, B. Kasprzyk-Hordern, Water Res. (2014).

[3] J.-J. Jiang, C.-L. Lee, M.-D. Fang, Mar. Pollut. Bull. 85 (2014) 391-399.

[4] R. Rosal, A. Rodríguez, J.A. Perdigón-Melón, M. Mezcua, M.D. Hernando, P. Letón, E. García-Calvo, A. Agüera, A.R. Fernández-Alba, Water Res. 42 (2008) 3719-3728.

[5] N. De la Cruz, J. Giménez, S. Esplugas, D. Grandjean, L.F. de Alencastro, C. Pulgarín, Water Res. 46 (2012) 1947-1957. 
[6] I. Oller, S. Malato, J.A. Sanchez-Perez, Sci. Total Environ. 409 (2011) 4141-4166. [7] I. Michael, L. Rizzo, C.S. McArdell, C.M. Manaia, C. Merlin, T. Schwartz, C. Dagot, D. Fatta-Kassinos, Water Res. 47 (2013) 957-995.

[8] H. Gallard, J. De Laat, B. Legube, Water Res. 33 (1999) 2929-2936.

[9] J.J. Pignatello, E. Oliveros, A. MacKay, Crit. Rev. Environ. Sci. Technol. 36 (2006) $1-84$.

[10] B.M. Souza, M.W.C. Dezotti, R.A.R. Boaventura, V.J.P. Vilar, Chem. Eng. J. 256 (2014) 448-457.

[11] D.R. Manenti, P.A. Soares, A.N. Módenes, F.R. Espinoza-Quiñones, R.A.R. Boaventura, R. Bergamasco, V.J.P. Vilar, Chem. Eng. J. 266 (2015) 203-212.

[12] H. Nakagawa, E. Yamaguchi, Chemosphere 88 (2012) 183-187.

[13] H.B. Abrahamson, A.B. Rezvani, J.G. Brushmiller, Inorg. Chim. Acta 226 (1994) $117-127$.

[14] J. Guo, Y. Du, Y. Lan, J. Mao, J. Hazard. Mater. 186 (2011) 2083-2088.

[15] Y. Chen, Z. Liu, Z. Wang, M. Xue, X. Zhu, T. Tao, J. Hazard. Mater. 194 (2011) 202-208.

[16] G. Liu, S. Zheng, X. Xing, Y. Li, D. Yin, Y. Ding, W. Pang, Chemosphere 78 (2010) 402-408.

[17] M.M. Rahman, R.B. Abdullah, W.E. Wan Khadijah, J. Anim. Physiol. Anim. Nutr. 97 (2013) 605-614.

[18] M.J. Farré, X. Doménech, J. Peral, J. Hazard. Mater. 147 (2007) 167-174.

[19] M. Kępczyński, A. Czosnyka, M. Nowakowska, J. Photochem. Photobiol. A: Chem. 185 (2007) 198-205.

[20] E. Lipczynska-Kochany, J. Kochany, Chemosphere 73 (2008) 745-750.
[21] N. Klamerth, S. Malato, M.I. Maldonado, A. Agüera, A. Fernández-Alba, Catal. Today 161 (2011) 241-246.

[22] Z. Yuan, J. Van Briesen, Environ. Eng. Sci. (2006) 533-544.

[23] C.K. Schmidt, M. Fleig, F. Sacher, H.J. Brauch, Environ. Pollut. 131 (2004) 107-124.

[24] A. Rastogi, S.R. Al-Abed, D.D. Dionysiou, Water Res. 43 (2009) 684-694.

[25] N.J. Velupula, G.J. Tedros, M.C. Andrew, Anal. Sci. 23 (2007) 493-496.

[26] N. Klamerth, S. Malato Rodríguez, A. Aguera, A. Fernández-Alba, Water Res. (2013) 833-840.

[27] S. Miralles-Cuevas, I. Oller, J.A.S. Pérez, S. Malato, Water Res. (2014).

[28] N. Klamerth, S. Malato, A. Aguera, A. Fernandez-Alba, G. Mailhot, Environ. Sci. Technol. 46 (2012) 2885-2892.

[29] P.J. Whitcomb, M.J. Anderson, Productivity Press, 2004.

[30] Y. Wu, M. Brigante, W. Dong, P. de Sainte-Claire, G. Mailhot, J. Phys. Chem. A 118 (2014) 396-403.

[31] W. Huang, M. Brigante, F. Wu, C. Mousty, K. Hanna, G. Mailhot, Environ. Sci. Technol. 47 (2013) 1952-1959.

[32] W. Huang, M. Brigante, F. Wu, K. Hanna, G. Mailhot, J. Photochem. Photobiol. A: Chem. (2012) 17-23

[33] J. Li, G. Mailhot, F. Wu, N. Deng, J. Photochem. Photobiol. A: Chem. (2010) $1-7$

[34] S. Metsarinne, T. Tuhkanen, R. Aksela, Chemosphere (2001) 949-955.

[35] N.R. Costa, J. Lourenço, Z.L. Pereira, Chemom. Intell. Lab. Syst. 107 (2011) 234-244. 